\title{
Regeneration of Olfactory Bipolar Neurons in the Normal Olfactory Epithelium of the Adult Bat
}

\author{
By \\ Masaru Yamamoto, Kazuko Uchida and Toshio Ito \\ Department of Anatomy, Teikyo University School of Medicine, \\ Kaga 2, Itabashi, Tokyo 173, Japan \\ -Received for Publication, April 17, 1976-
}

\section{Introduction}

The pseudostratified olfactory epithelium is composed of olfactory cells (sensory or receptor cells), supporting cells and basal cells. It is well established that the olfactory cells are bipolar neurons sending out a dendrite toward the luminal surface of the olfactory epithelium to make there a ciliated swelling named olfactory vesicle or dendritic bulb (Yamamoto, 1976) and a neurite or axon toward the base of the epithelium to make there small bundles which constitute, in the underlying connective tissue, olfactory nerves.

The question concerning the regeneration of olfactory epithelium, especially of the olfactory bipolar neurons in adult vertebrates has been a controversial subject in the biology as recently reviewed by Graziadei (1972), because the nerve cells have been believed to be nonreplaceable in adult vertebrates. Recently, however, it has been shown by Graziadei (1973), by Graziadei and Metcalf $(1970,1971)$ in autoradiographic frog material, by Matulionis (1974) and by Mulvaney and Heist (1971a, b) in zinc sulfate-destroyed rodent olfactory epithelium that the olfactory cell can regenerate. In addition, Mulvaney and Heist have assumed by observation of centriole migration in developing and adult rabbit olfactory cells that the differentiation or development of these neurons persists in fully-developed tissue from adult animals. In normal untreated vertebrate olfactory epithelium, the existence of stem cells or juvenile precursors of olfactory epithelial cells has been proposed by several investigators, who termed them by various names (Okano, 1965; Okano et al., 1977; Andres, 1969; Graziadei and Metcalf, 1970, 1971; Graziadei, 1972, 1973). They have mostly been detected in the basal cell layer of the olfactory epithelium, although some authors have assumed that ducts or glands of Bowman might furnish stem cells for 
olfactory epithelial regeneration (Mulvaney and Heist, 1971a ; Matulionis, 1974).

Despite the positive results of olfactory cell regeneration as described above, the direct morphological data showing the fine structural sequences of the regeneration of olfactory neurons from the precursors have completely been lacking. The ultrastructural findings which will be described in this paper are thought to make up this deficiency.

\section{Material and Method}

Olfactory epithelia were obtained from two wild bats (Rhinolophus ferrum-equinum nippon) and fixed by immersion or perfusion with 2.5 $\%$ glutaraldehyde and post-fixed in $1 \% \mathrm{OsO}_{4}$. After the routine processing, sections were cut and stained with uranyl acetate and Sato's lead solution (Sato, 1968), and examined with a JEM 100C electron microscope. The details of the procedures were given in the recent paper published by Yamamoto (1976).

\section{Results and Discussion}

Yamamoto (1976) has confirmed, in the bat olfactory epithelium, the occurrence of the so-called interstitial or intercalated cells (I-cells) in a considerable number in the region between perikarya of olfactory cells and basal cell layer (Fig. 1,2). These irregular-shaped cells with a pale cytoplasm and a relatively large nucleus of pale appearance reach neither luminal nor basal surface of the olfactory epithelium. The Icells are characterized by adundant free ribosomes distributed in the entire cytoplasm, but they contain scanty cisternae of rough endoplasmic reticulum, sparse short mitochondria and a small Golgi complex in the supranuclear area. All these ultrastructural features together with the content of a large pale nucleus suggest that these cells may be undifferentiated epithelial cells comparable also with the embryonic olfactory epithelial cells described by Cuschieri and Bannister (1975). Among these undifferentiated cells mitotic figures are found (Fig. 1), and from this evidence it is assumed that the I-cells might have probably originated, through mitotic division, from undifferentiated basal cells, which were distinguished by Yamamoto (1976); he supposed in his paper that the I-cells would be precursors both of the olfactory and supporting cells of the olfactory epithelium.

Procentriole assembly in the I-cell

In this electron microscopic investigation, the formation sequences of multiple centrioles probably destined to the basal bodies of the olfactory cilia, and their migration toward the apical end have been 
revealed in the I-cells and thus evidences have been established to indicate that at least some of these cells may develop and differentiate into the olfactory bipolar neurons. As shown in Figure 3A, an I-cell has been observed, which possesses in the supranuclear area a cluster of centrioles, probably of immature procentrioles. In this cluster, several procentrioles are almost circularly arranged around a dense, finely granular mass (core) in the center and some longitudinally sectioned procentrioles are oriented radially around the dense core. Investigators who have recently been engaged in the ultrastructural studies on the centriole morphogenesis and ciliogenesis in developing vertebrate ciliated epithelia have observed the same complex structure, and designated them as the assembly of the procentrioles (Kalnins and Porter, 1969 ; Kalnins, Chung and Turnbull, 1972) or as the generative complex (Dirksen, 1971). According to them, the central dense cylindrical or hollow mass had been produced in association with the preexisting mature centrioles, and as the procentrioles developed and matured, they separated from clusters and migrated to the apical cell end to become basal bodies of cilia. The procentrioles assembled in the characteristic cluster found in the I-cells of the adult bat may have probably been formed in the same manner under the influence of the mature centrioles of the last mitosis. As revealed in the developing ciliated epithelia, they probably develop further, mature and separate from the assembly to furnish basal bodies of olfactory cilia. And during these developmental processes the centriole migration (Mulvany and Heist, 1971b) may occur.

Migration of centriole clusters in I-cells

In a recent electron microscopic study on the morphogenesis of the mouse olfactory mucosa, the procentriole cluster and migration toward the apical end of the olfactory cell have also been remarked (Cuschieri and Bannister, 1975). In the bat olfactory epithelium there have further been observed such I-cells which have more developed and elongated toward the luminal surface of the epithelium sending out an attenuated projection, namely the dendrite (Fig. 6), and groups of centrioles (or procentrioles), derived probably from the procentriole assembly, have been detected in various locations of the elongated cytoplasm (Fig. 3B,6), suggesting that they are migrating toward the apical end of cells, which should be, in this differentiation state, designated as immature olfactory cells. In Figure 3B, centriole groups are seen both in the deeper and the apical portion near the luminal end of immature olfactory cells. In the latter location approximately 10 centrioles are aggregated into a loose group. At a higher magnification (Fig. 4), the centrioles in the group are somewhat irregularly arranged, so that their exact cross and longitudinal sections are not detectable. The apical 
cytoplasm around the centrioles contains abundant free ribosomes, which partially make polysomes, scanty cisternae of the rough endoplasmic reticulum, smooth vesicles and elongated mitochondria. These cytological findings naturally indicate that this apical cytoplasmic area containing the centriole group may be transformed before long into a dendritic bulb (olfactory vesicle). The occurrence of microtubules (neurotubules) running parallel to the long axis of the cell suggests the

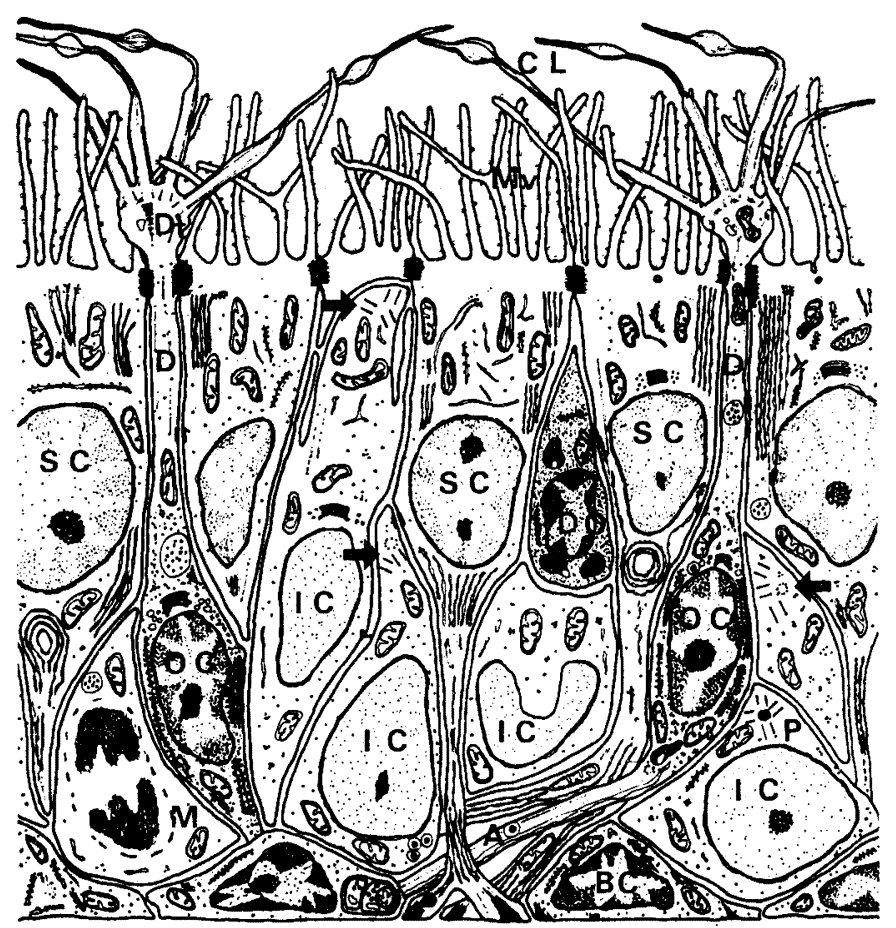

Textfig. 1. Schematic representation of the olfactory epithelium containing many interstitial cells (IC) in various differentiation stages to olfactory cells. Among interstitial cells proliferating by mitosis (M) there are those which possess a procentiole assembly $(P)$ in the supranuclear region. These interstitial cells (bipolar neurons) elongate then upward sending out an attenuated process (dendrite) toward the free surface of the olfactory epithelium. Centriole clusters derived from the assembly migrate gradually toward the apical end of the process where the centriole cluster is taken up in the newly-formed olfactory vesicle to become basal bodies of the olfactory cilia, so that upward migrating centriole clusters (arrows) are demonstrated in various locations of the dendritic process. In this way the regeneration of the olfactory cell (bipolar neuron) from the in. terstitial cell proceeds to replace degenerative olfactory cell (DO) usually found in the olfactory epithelium.

$\mathrm{A}$, axon (neurite) of the olfactory cell; $\mathrm{BC}$, basal cell; CL, olfactory cilia; D, dendrite of the olfactory cell; Dt, olfactory vesicle; $\mathrm{Mv}$, microvilli of supporting cell bearing numerous minute polypoid processess; OC, olfactory cell; SC, supporting cell. 
advanced differentiation of this immature olfactory cell (Fig. 3B). Large dense-cored vesicles measuring about $1200 \AA$ in diameter, which were demonstrated for the first time by Yamamoto (1976) in the bat olfactory bipolar neurons, have been occasionally revealed in a considerable number, making a small accumulation also in the differentiating or immature olfactory cell (Fig. 5).

The present study failed to demonstrate actually the formation of the olfacotry vesicle and the ciliogenesis of the olfacotry cilia from the basal bodies derived from the centrioles; it has, however, sufficiently been proved that the olfactory bipolar neurons can regenerate even in the normal adult olfactory epithelium from the undifferentiated precursors, probably derived from the basal cell. The regenerated olfactory cells may replace the degenerated olfactory cells which are not rarely detectable in the normal olfactory epithelium of the bat.

\section{Summary}

Regeneration of olfactory cells (bipolar neurons) has been revealed in the normal olfacotry epithelium of the adult bat. Some of the interstitial cells detectable between the perikarya of the olfactory cells and the basal cell layer of the epithelium are referred to as the precursors of the olfactory bipolar neurons. It is further suggested that other interstitial cells may probably participate in the regeneration of supporting cells of the olfactory epithelium.

\section{References}

Andres, K. H.: Der olfactorische Saum der Katze. Z. Zellforsch., 96: 250-274, 1969.

Cuschieri, A. and L. H. Bannister: The development of the olfactory mucosa in the mouse: electron microscopy. J. Anat., 119: 471-498, 1975.

Dirksen, E. R. : Centriole morphogenesis in developing ciliated epithelium of the mouse oviduct. J. Cell Biol., 51: 286-302, 1971.

Graziadei, P.P.C.: The ultrastructure of vertebrates olfactory mucosa. In "The Ultrastructure of Sensory Organs". I. Friedmann (ed.). American Elsevier, 1972.

- Cell dynamics in the olfactory mucosa. Tissue \& Cell, 5: 113-131, 1973.

Graziadei, P. P.C. and J.F. Metcalf: Autoradiographic study of frog's olfactory mucosa. Amer. Zool., 10:559, 1970.

- and - Autoradiographic and ultrastructural observations on the frog's olfactory mucosa. Z. Zellforsch., 116:305-318, 1971.

Kalnins, V.I., C.R. Chung and C. Turnbull: Procentrioles in ciliating and ciliated cells of chick trachea. Z. Zellforsch., 135: 461-471, 1972.

Kalnins, V. I. and K. R. Porter: Centriole replication during ciliogenesis in the chick tracheal epithelium. Z. Zellforsch., 100:1-30, 1969.

Matulionis, D.H.: Ultrastructural study of mouse olfactory epithelium following distruction by $\mathrm{ZnSO}_{4}$ and its subsequent regeneration. Am. J. Anat., 142: 69-90, 1974. 
Mulvaney, B. D. and H. E. Heist: Regeneration of rabbit olfactory epithelium. Am. J. Anat., 131: 241-252, 1971a.

and - Centriole migration during regeneration and normal development of olfactory epithelium. J. Ultrastr. Res., 35: 274-281, $1971 \mathrm{~b}$.

Okano, M.: Fine structure of the canine olfactory hairlets. Arch. histol. jap., 26 : $169-185,1965$.

Okano, M., A.F. Weber and S. P. Frommes: Electron microscopic studies of the distal border of the canine olfactory epithelium. J. Ultrastr. Res., 17: 487-502, 1967.

Yamamoto, M.: An electron microscopic study of the olfactory mucosa in the bat and rabbit. Arch. histol. jap., 38 : 359-412, 1976. 


\section{PLATES}




\section{Explanation of Figures}

\section{Plate I}

Fig. 1. A survey electron micrograph of the perpendicularly sectiond olfactory epithelium of the bat. Supporting cells (S), olfactory cells (O), basal cells (B) and interstitial cells (I) are distinguished. Interstitial cells and a mitotic figure of the interstitial cell are seen between perikarya of the olfactory cells and the basal cell layer. L, wandering cell; OV, olfactory vesicle; arrows indicate microvilli of the supporting cell. $\times 2100$

Inset: The mitotic figure of the interstitial cell (M). $\times 3200$

Fig. 2. Transverse section of the bat olfactory epithelium cut along the plane close to the perikaryon of olfactory cell (OC). In two interstitial cells (IC) relatively large nuclei appear light and are surrounded by narrow and pale cytoplasmic layers which mainly contain free ribosomes and scanty mitochondria like the embryonic cells. In the clear cytoplasm of supporting cells (SC) tubular profiles of the smooth endoplasmic reticulum and mitochondria are conspicuous. Here and there desmosomes (arrows) and cross sections of axons of olfactory cells are seen between epithelial cells. $\times 8800$ 
Plate I
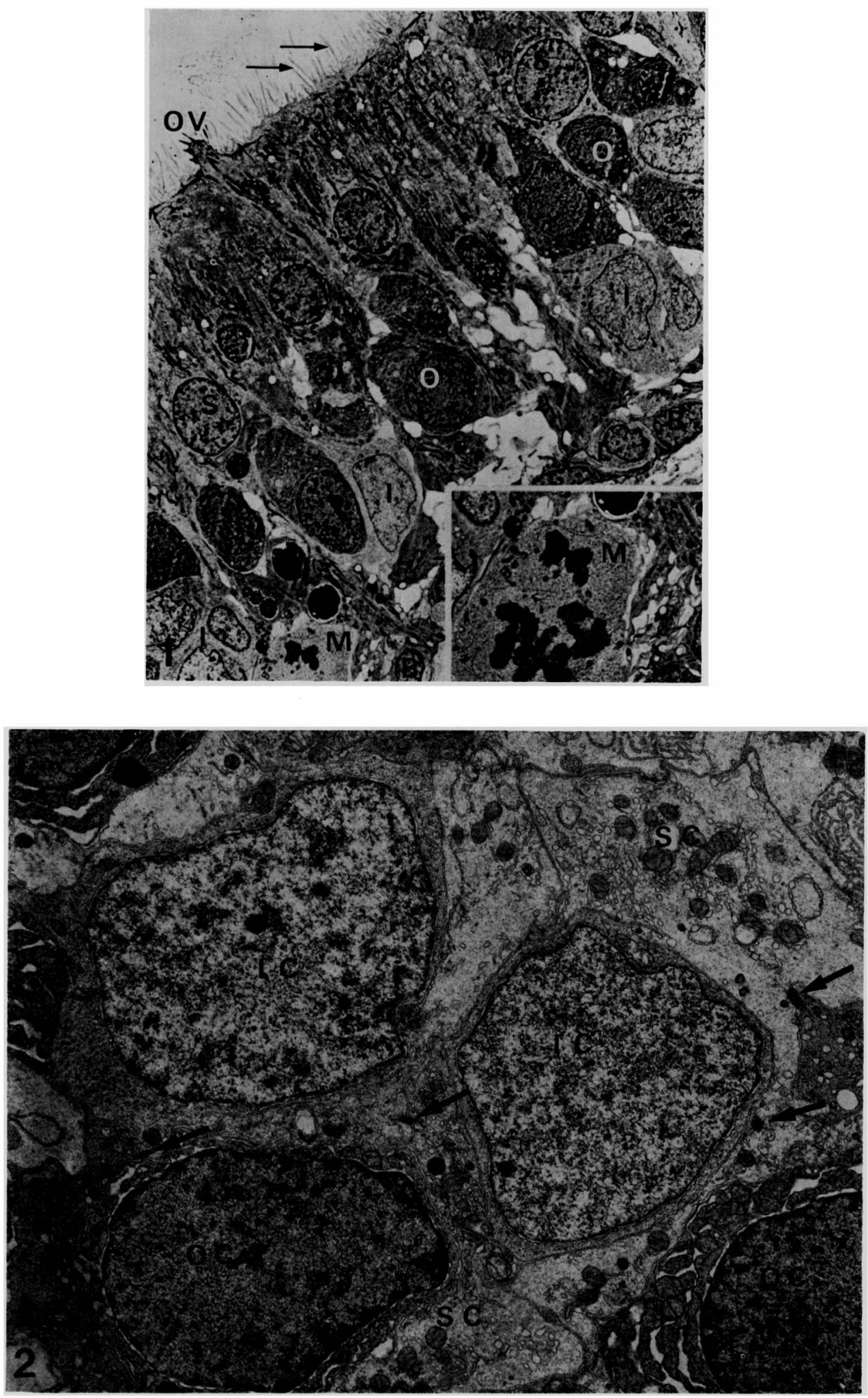


\section{Plate II}

Fig. 3. A) A procentriole assembly (arrow) in the supranuclear region of an interstitial cell (IC). In the procentriole assembly many procentrioles are circularly arranged around a dense core and among them longitudinally cut procentrioles are radially oriented. $\mathrm{BC}$, basal cell layer; $\mathrm{Bm}$, basement membrane; $\mathrm{Cn}$, connective tissue; L, wandering cell. $\times 6000$

B) Two centriole clusters are seen both in the deeper region (C2) and in the apical region $(\mathrm{Cl})$ of dendritic processes of two interstitial cells (immature olfactory cells) toward the free surface of the olfactory epithelium. These different locations of centriole clusters probably derived from the procentriole assemblies may suggest the centriole migration toward the apical end of the dendrite where they are taken up in the olfactory vesicle to become basal bodies of olfactory cilia. SC, supporting cell; IC, interstitial cell; OCD, degenerative olfactory cell; OV, olfactory vesicles. $\times 6000$ 
Plate II

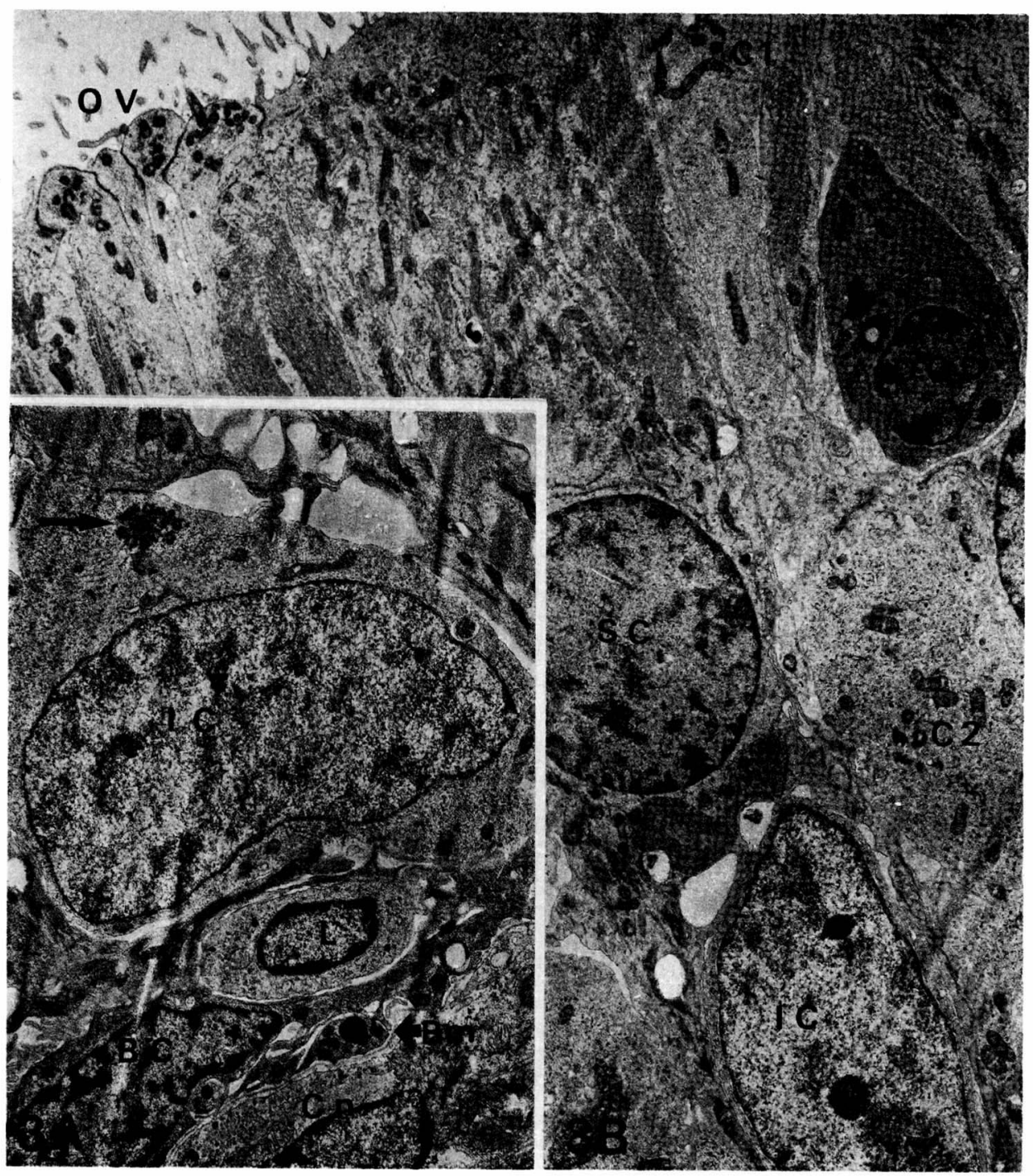




\section{Plate`III}

Fig. 4. Higher magnification of the centriole cluster in the apical region $(\mathrm{Cl})$ of the cytoplasmic process of the interstitial cell (immature olfactory cell) depicted in Fig. 3B. The apical cytoplasm surrounding this centriole cluster may become an olfactory vesicle provided with olfactory cilia; it contains numerous free ribosomes, some of which make polysomes, sparse cisternae of $\mathrm{rER}$, some smooth vesicles of variable sizes and mitochondria, showing not-fully differentiated cytological appearances different from neighboring mature sup. porting cells (SC) with abundant tubular profiles of the smooth endoplasmic reticulum. F, free surface of the epithelium. $\times 19800$

Fig. 5. Infranuclear portion (IC) of an interstitial cell probably in a stage of the advanced differentiation toward the olfactory cell. A cluster of large dense cored vesicles (ca 1200A in diameter) are embedded in the ribosome-rich cytoplasm. $\times 20000$

Fig. 6. Transformation of an interstitial cell (OCR) into the immature olfactory cell sending out a dendritic process toward the apical surface of the olfactory epithelium which contains a centriole clustere (arrow) in the superficial portion far away from the nucleus. SC, supporting cells. $\times 8400$ 
Plate III
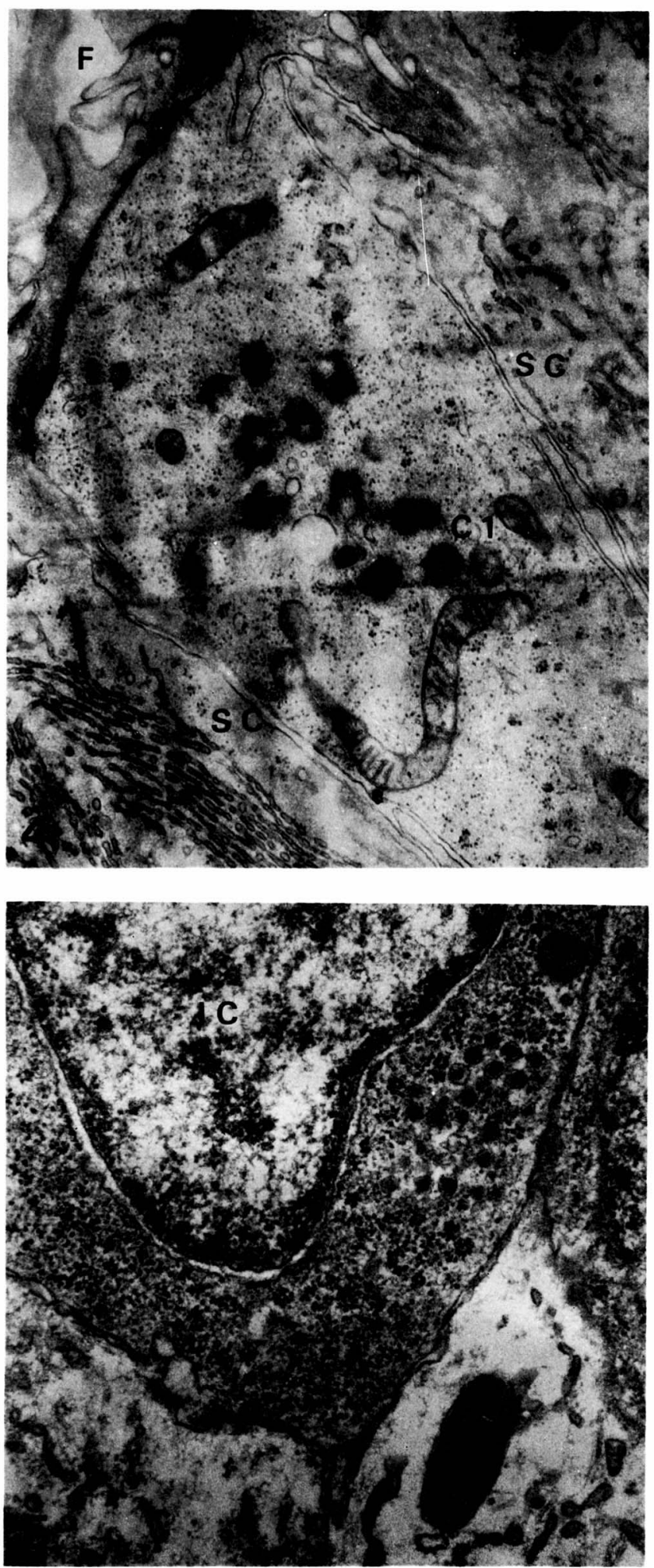

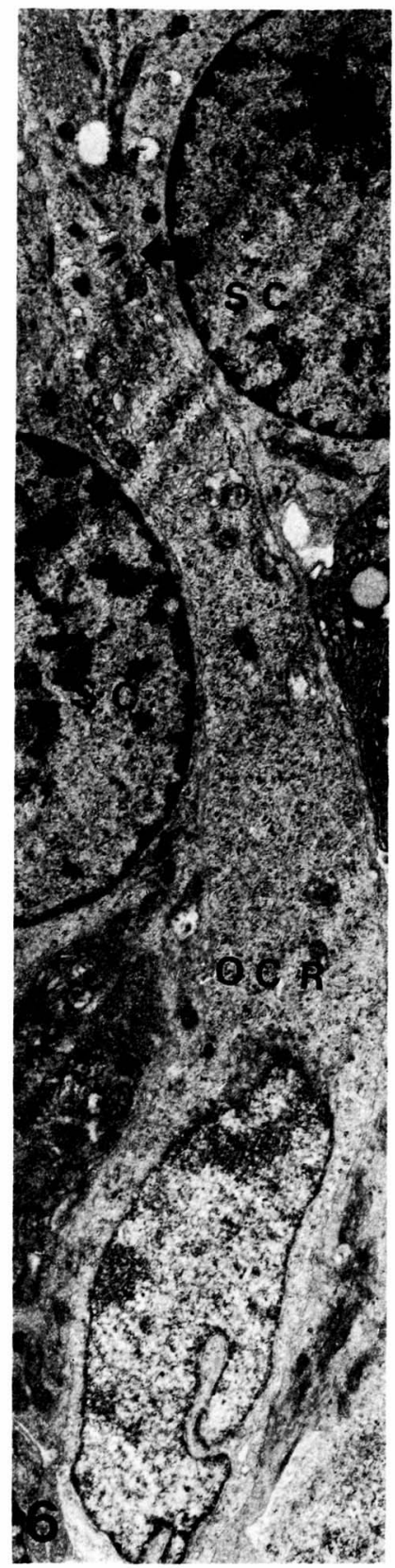

